\title{
Raman and TGA Study of Carbon Nanotubes Synthesized Over Mo/Fe Catalyst on Aluminium Oxide, Calcium Carbonate and Magnesium Oxide Support
}

\author{
EZEKIEL DIXON DIKIO*, NTAOTE DAVID SHOOTO, \\ FORCE TEFO THEMA and ABDULLAHI MOHAMED FARAH
}

Applied Chemistry and Nanoscience Laboratory, Department of Chemistry, Faculty of Applied and Computer Science, Vaal University of Technology, P.O Box X021, Vanderbijlpark, South Africa

ezekield@vut.ac.za

Received 8 January 2013 / Accepted 14 February 2013

\begin{abstract}
Carbon nanomaterials were synthesized from $\mathrm{Al}_{2} \mathrm{O}_{3}, \mathrm{CaCO}_{3}$ and $\mathrm{MgO}$ used as support materials without a catalyst and over $\mathrm{Mo} / \mathrm{Fe}$ catalyst on $\mathrm{Al}_{2} \mathrm{O}_{3}, \mathrm{CaCO}_{3}$ and $\mathrm{MgO}$ as support materials. The as-prepared nanomaterials were characterized by Raman spectroscopy, Thermogravimetric and Derivative thermogravimetric analysis (TGA \& DTA). The intensity ratios $\left(I_{D} / I_{G}\right)$, of the $D$ - and $G$-bands were higher for $\mathrm{Al}_{2} \mathrm{O}_{3}, \mathrm{CaCO}_{3}$ and $\mathrm{MgO}$ as support materials and lower for $\mathrm{Mo} / \mathrm{Fe} / \mathrm{Al}_{2} \mathrm{O}_{3}, \mathrm{Mo} / \mathrm{Fe} / \mathrm{CaCO}_{3}$ and $\mathrm{Mo} / \mathrm{Fe} / \mathrm{MgO}$. The ratios of the $s p^{2} / s p^{3}$ bonded carbon were lower in the support than in the catalyst and support. TGA and DTA curves show $\mathrm{MgO}$ and $\mathrm{Mo} / \mathrm{Fe} / \mathrm{Al}_{2} \mathrm{O}_{3}$ lost $37.39 \%$ and $11 \%$ mass respectively while $\mathrm{Mo} / \mathrm{Fe} / \mathrm{CaCO}_{3}$ and $\mathrm{Mo} / \mathrm{Fe} / \mathrm{MgO}$ barely decomposed under high temperatures.
\end{abstract}

Keywords: Carbon nanotubes, Raman spectroscopy, Thermogravimetric analysis, Derivative thermogravimetric analysis, SEM, EDS, XRD

\section{Introduction}

There are widespread kinds of carbon nanostructures, but they all have a few elementary things in common. First, all of these nanostructures are primarily made up of the element carbon and all these artefacts are called carbon allotropes. The range of these materials starts with the well-known allotrope "graphite" and continues on to incorporate fullerenes, graphene and more complex structures such as carbon nanotubes ${ }^{1}$.

Carbon nanomaterials have given the material sciences and the chemistry of carbon a new direction in recent years. Different carbon nanomaterials offer an extensive range of beneficial properties relating to electrical conductivity, thermal resistance, and exceptional strength, making them attention-grabbing materials to a broad range of industries ${ }^{2}$.

Carbon nanotubes were found ${ }^{3}$ by scientific observation in 1991. Carbon nanotubes are molecular scale tubes of graphitic carbon with outstanding properties. They are among the 
stiffest and strongest fibres known and have remarkable optical, electronic and mechanical properties and many other unique characteristics ${ }^{4}$. For these reasons they have attracted considerable academic and industrial interest and worldwide attention in both fundamental and technological perspectives owing to their broader-scope of interested properties ${ }^{5}$.

Many different methods have been employed for the synthesis of (CNTs), methods such as chemical vapor deposition $(C V D)^{6,7}$, laser ablation ${ }^{8,9}$ and arch discharge ${ }^{10,11}$. Since catalytic chemical vapor deposition (CVD) is a simple and relatively cheap technique, it might be the most promising method for large-scale production of carbon nanotubes under reasonably mild conditions. Additionally, with the CVD method, the growth of carbon nanotubes like selectivity of other catalytic reaction can be successfully controlled by adjusting the reaction conditions and preparing proper catalyst ${ }^{12}$.

Raman spectroscopy is a simple and powerful technique to identify and study different types of carbon nanotubes it generates data pertaining to the purity, defects, tube alignment and assist in distinguishing between the presence of carbon nanotubes and relative carbon allotropes. Thermogravimetric analysis, (TGA) determines the mass change of a substance measured as function of temperature whilst the substance is subjected to a controlled temperature programme. It has been found a single metal and mixture of metals supported on oxides, clays or zeolites have great contribution in terms of catalytic activity to nanotubes synthesis ${ }^{13-15}$. Dispersion and stabilization of the metallic catalyst materials can also be performed by using a number of oxides and mixed oxides. It is well known that the catalytic properties of the catalyst-support material combine strongly depending on the interaction between catalyst and the support material.

In this paper we present Raman and thermogravimetric analysis of carbon nanotubes synthesized in a CCVD reactor over molybdenum and iron catalyst supported on aluminium oxide $\left(\mathrm{Al}_{2} \mathrm{O}_{3}\right)$, calcium carbonate $\left(\mathrm{CaCO}_{3}\right)$ and magnesium oxide $(\mathrm{MgO})$. Nanomaterial obtained from the support materials only, aluminium oxide, calcium carbonate and magnesium oxide, without a catalyst, were also studied to identity the effect of the support on the as-prepared carbon nanotube. The as-prepared nanomaterial were characterized by SEM, EDS, TEM and XRD.

\section{Experimental}

All chemicals used in this research were of analytical grade. All solutions were prepared with deionized water. All chemicals were purchased from sigma-Aldrich and no further purification were performed on the chemicals, they were all used as they were from the manufacturer.

\section{Preparation of catalyst}

A mixture of ammonium molybdate $\left(\left(\mathrm{NH}_{4}\right)_{5} \mathrm{Mo}_{7} \cdot 4 \mathrm{H}_{2} \mathrm{O}\right)$, citric acid $\left(\mathrm{C}_{6} \mathrm{H}_{8} \mathrm{O}_{7} \cdot \mathrm{H}_{2} \mathrm{O}\right)$ and iron(III) nitrate $\left(\mathrm{Fe}\left(\mathrm{NO}_{3}\right)_{3}\right)$ respective masses $0.074 \mathrm{~g}, 4.266 \mathrm{~g}$ and $1.647 \mathrm{~g}$ were dissolved in $50 \mathrm{~mL}$ deionized water in a beaker ${ }^{16-19}$. A mixture was gently heated at $50{ }^{\circ} \mathrm{C}$ to avoid splatter; solution was heated up to a time that it crystalized. The formed crystals were placed in an oven and baked at $150{ }^{\circ} \mathrm{C}$ over-night (12 h). Hard solid crystals were crashed into power.

\section{Synthesis of carbon nanotubes}

Catalytic chemical vapour deposition method was used the synthesis of carbon nanotubes. The reactor consists of a tube furnace with a quartz tube $70 \mathrm{~cm}$ long and $40 \mathrm{~mm}$ diameter, and temperature controller. The catalyst was placed on a quartz boat and placed in the middle 
of the quartz tube then inserted in the furnace. The furnace was heated for $85 \mathrm{~min}$. at a rate $10{ }^{\circ} \mathrm{C} / \mathrm{min}$. in an inert atmosphere of nitrogen gas, to reach the desired temperature $\left(85^{\circ} \mathrm{C}\right)$ once reached the target temperature was kept constant at $850{ }^{\circ} \mathrm{C}$. Then a mixture of acetylene $\left(\mathrm{C}_{2} \mathrm{H}_{2}\right)$, at a flow rate of $45 \mathrm{~mL} / \mathrm{min}$ and nitrogen at $150 \mathrm{~mL} / \mathrm{min}$ was introduced into the quartz tube for $80 \mathrm{~min}$ for the fabrication of carbon nanotubes. After the reaction had ceased the quartz tube was cooled to room temperature in a nitrogen atmosphere, and graphitic crystalline carbon was collected for characterization.

\section{Characterization}

The morphological features of the as-prepared carbon nanotubes were analyzed by Raman spectroscopy and Thermogravimetric analyser. The Raman spectra were obtained by a Raman spectroscopy, Jobin-Yvon HR800 UV-Vis-NIR Raman spectrometer equipped with an Olympus BX 40 attachment. The excitation wavelength was $514.5 \mathrm{~nm}$ with an energy setting of $1.2 \mathrm{mV}$ from a coherent Innova model 308 argon-ion laser. The Raman spectra were collected by means of back scattering geometry with an acquisition time of 50 seconds. The surface morphology, SEM and EDS measurements were recorded with a JEOL 7500F Field Emission scanning electron microscope. The HR-TEM images of the sample were obtained by a CM 200 electron microscope operated at $100 \mathrm{kV}$. The thermal behaviour of the carbon nanotube and the catalyst were investigated by TGA using a Perkin Elmer Simultaneous Thermal Analyzer (STA 6000) under a nitrogen environment. The as-prepared carbon nanotube sample was heated in platinum crucibles with nitrogen gas flow rate of $19.7 \mathrm{~mL} / \mathrm{min}$ and a gas pressure of 4.0 bars. The dynamic measurement was made from $30{ }^{\circ} \mathrm{C}$ and $950{ }^{\circ} \mathrm{C}$ with a ramp rate of $30{ }^{\circ} \mathrm{C} / \mathrm{min}$ to $900{ }^{\circ} \mathrm{C}$. Powder X-ray diffraction (PXRD) patterns were collected with a Bruker AXS D8 Advanced diffractometer operated at $45 \mathrm{kV}$ and $40 \mathrm{~mA}$ with monochromated copper $\mathrm{K} \alpha 1$ radiation of wavelength $(\lambda=1.540598)$ and $\mathrm{K} \alpha 2$ radiation of wavelength $(\lambda=1.544426)$. Scan speed of $1 \mathrm{~s} / \mathrm{step}$ and a step size of $0.03^{\circ}$.

\section{Results and Discussion}

Raman spectroscopy is an elementary technique used to identify and study different kinds of carbon nanotubes, it yields information about the purity, defects and contributes in the distinction of carbon nanotubes and other carbonaceous materials. The support materials, aluminium oxide, calcium carbonate and magnesium oxide without catalyst were placed in the CCVD reactor separately with acetylene and nitrogen gas passed over the support as it is heated. After the samples were cooled, the as-prepared material were analysed by Raman spectroscopy. The Raman spectra for the as-prepared carbon nanomaterial obtained with the support material in the absence of a catalyst is presented in Figure 1(a-c). Table 1 show the peak height and intensity of the $T$-, $D$ - and $G$-bands and their $I_{D} / I_{G}$ ratios. The Raman spectra of the support material only show characteristic bands of multiwall carbon nanotubes. Three bands are observed at 1121,1339 and $1588 \mathrm{~cm}^{-1}$ for aluminium oxide, Figure 1(a), at 1122 , 1301 and $1562 \mathrm{~cm}^{-1}$ for calcium carbonate, Figure 1(b) and at 1122,1318 and $1566 \mathrm{~cm}^{-1}$ for magnesium oxide, Figure 1(c). The peak observed at 1121, 1122 and $1122 \mathrm{~cm}^{-1}$ in the spectra for aluminium oxide, calcium carbonate and magnesium oxide respectively is assigned as T-band originating from $s p^{3}$ bonded carbon and it is sensitive to small changes in $s p^{3}$ content $^{20}$. The peak at 1339,1301 and $1318 \mathrm{~cm}^{-1}$ in the spectra for aluminium oxide, calcium carbonate and magnesium oxide respectively correspond to the $D$-band of disordered graphitic carbon in carbon nanotubes. The peak at 1588,1562 and $1566 \mathrm{~cm}^{-1}$ in the spectra for aluminium oxide, calcium carbonate and magnesium oxide respectively corresponds to the $G$-band of graphitic carbon in carbon nanotubes. The $D$ - and $G$-bands 
indicate the presence of crystalline graphitic carbon in carbon nanotubes. The presence of these two peaks is evidence that the support material could be used as a catalyst in itself in the synthesis of carbon nanotubes. The $D$-bands have been attributed to the presence of amorphous carbon due to surface defects of carbon nanotubes while the $G$-bands are due to the presence of ordered graphitic carbon nanotubes in the prepared samples. The $D$ - and $G$ bands in the Raman spectra produce an overtone which resonates at about $2600 \mathrm{~cm}^{-1}$. No overtone is observed in the Raman spectra of the support materials, indicating the low quality of carbon nanotubes synthesized. The intensity ratio of the two peaks, $\left(I_{D} / I_{G}\right)$, considered a parameter in characterizing the quality of carbon nanotubes synthesized, a higher intensity ratio indicate a higher degree of disorder in the carbon nanotube. The intensity ratio for the two peaks in aluminium oxide and magnesium oxide, Figure 1(a) and (c) are 1.142 and 1.014 respectively, indicating the presence of low quality carbon nanotubes. The $\left(I_{D} / I_{G}\right)$ for calcium carbonate, Figure $1(\mathrm{~b})$, of 0.056 show the presence of high quality carbon nanotube. The low height of the peak show very low quantity of carbon nanotubes was formed.
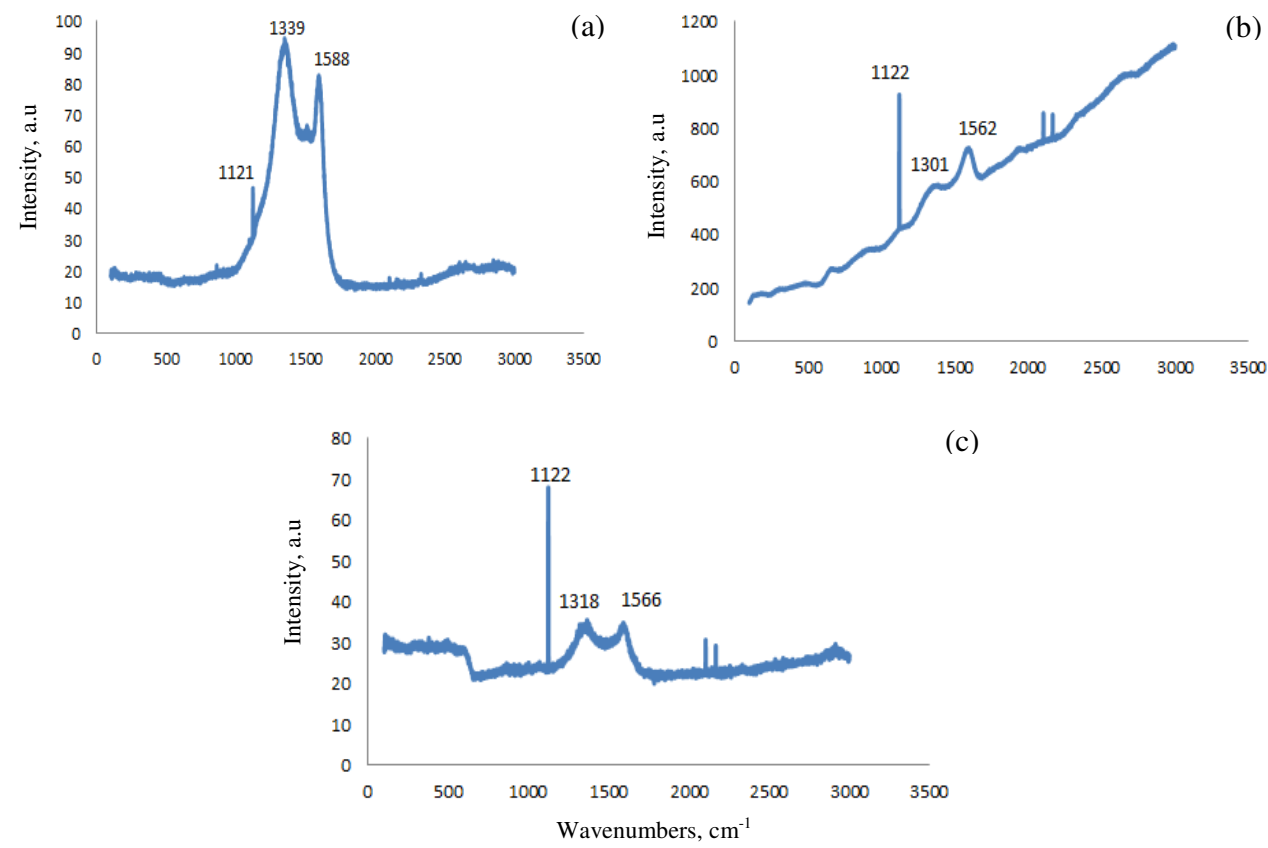

(c)

Figure 1. Raman spectra of support material only used in the synthesis of carbon nanotubes without a catalyst, (a) aluminium oxide, (b) calcium carbonate and (c) magnesium oxide

Table 1. Table of $T$-band peak height and intensity, $D$ - and $G$-band peak height and intensity and ratio of $D$ - and $G$-bands obtained from Raman spectra of carbon nanotube synthesized with catalyst support only

\begin{tabular}{cccccccc}
\hline \multirow{2}{*}{$\begin{array}{c}\text { Support } \\
\text { material }\end{array}$} & \multicolumn{2}{c}{ T-Band } & \multicolumn{2}{c}{$D$-Band } & \multicolumn{2}{c}{$G$-Band } & $I_{D} / I_{G}$ \\
\cline { 2 - 8 } & $\begin{array}{c}\text { Peak, } \\
\mathrm{cm}^{-1}\end{array}$ & $\begin{array}{c}\text { Intensity, } \\
\text { au }\end{array}$ & $\begin{array}{c}\text { Peak, } \\
\mathrm{cm}^{-1}\end{array}$ & $\begin{array}{c}\text { Intensity, } \\
\text { au }\end{array}$ & $\begin{array}{c}\text { Peak, } \\
\mathrm{cm}^{-1}\end{array}$ & $\begin{array}{c}\text { Intensity, } \\
\text { au }\end{array}$ \\
\hline $\mathrm{Al}_{2} \mathrm{O}_{3}$ & 1121 & 44.45 & 1339 & 92.15 & 1588 & 80.66 & 1.142 \\
$\mathrm{CaCO}_{3}$ & 1122 & 542.5 & 1301 & 8.6 & 1562 & 153.0 & 0.056 \\
$\mathrm{MgO}$ & 1122 & 67.94 & 1318 & 33.49 & 1566 & 33.04 & 1.014 \\
\hline
\end{tabular}


The Raman spectra of the as-prepared carbon nanomaterial with $\mathrm{Mo} / \mathrm{Fe}$ catalyst on aluminium oxide, calcium carbonate and magnesium oxide support respectively are presented in Figure 2 (a-c). Table 2 show peak heights and intensity of the $D$-and $G$-bands, the peak height and intensity of the overtone band and the intensity ratio of the $D$ - and $G$ bands. The Raman spectra for the supported catalyst, show peaks at 1332, 1343 and $1332 \mathrm{~cm}^{-1}$ respectively, that corresponds to the $D$-band of graphitic carbon. The $G$-band that indicates the presence of ordered graphitic carbon nanotubes are observed at 1581, 1576 and $1585 \mathrm{~cm}^{-1}$ respectively ${ }^{21}$. The presence of the $D$ - and $G$-bands in the as-prepared sample strongly suggests the presence amorphous and ordered graphitic carbon in the sample. An overtone peak is observed in the spectra for $\mathrm{Mo} / \mathrm{Fe} / \mathrm{CaCO}_{3}$, figure 2 (b) at $2670 \mathrm{~cm}^{-1}$. The presence of this resonance peak in the synthesis could be related to the amount of carbon nanotubes produced as well as their purity. The absence of this resonance peak in the asprepared carbon nanomaterial obtained from $\mathrm{Mo} / \mathrm{Fe} / \mathrm{Al}_{2} \mathrm{O}_{3}$ and $\mathrm{Mo} / \mathrm{Fe} / \mathrm{MgO}$, Figure $2(\mathrm{a} \& \mathrm{c})$ and its presence in the as-prepared carbon nanomaterial synthesized from the catalyst system $\mathrm{Mo} / \mathrm{Fe} / \mathrm{CaCO}_{3}$, Figure $2(\mathrm{~b})$, is an indication that the catalyst system $\mathrm{Mo} / \mathrm{Fe} / \mathrm{CaCO}_{3}$, produced a better and purer yield of carbon nanotubes compared to the others. The intensity ratio of the two peaks, $\left(I_{D} / I_{G}\right)$, which provide insight regarding the quality of carbon nanotube synthesized are found to be 1.0533 for $\mathrm{Mo} / \mathrm{Fe} / \mathrm{Al}_{2} \mathrm{O}_{3}, 0.9953$ for $\mathrm{Mo} / \mathrm{Fe} / \mathrm{CaCO}_{3}$ and 0.9748 for $\mathrm{Mo} / \mathrm{Fe} / \mathrm{MgO}$. A high intensity ratio indicates a high degree of disorder in the carbon nanotube synthesized. This data again confirms the quality of the nanomaterial produced from the catalyst system $\mathrm{Mo} / \mathrm{Fe} / \mathrm{CaCO}_{3}$. The spectra of the as-prepared sample obtained with the catalyst over calcium carbonate support, Figure 2(b), in addition to the $D$ - and $G$-bands and the overtone peak, show additional peaks at 213, 276 and $377 \mathrm{~cm}^{-1}$.
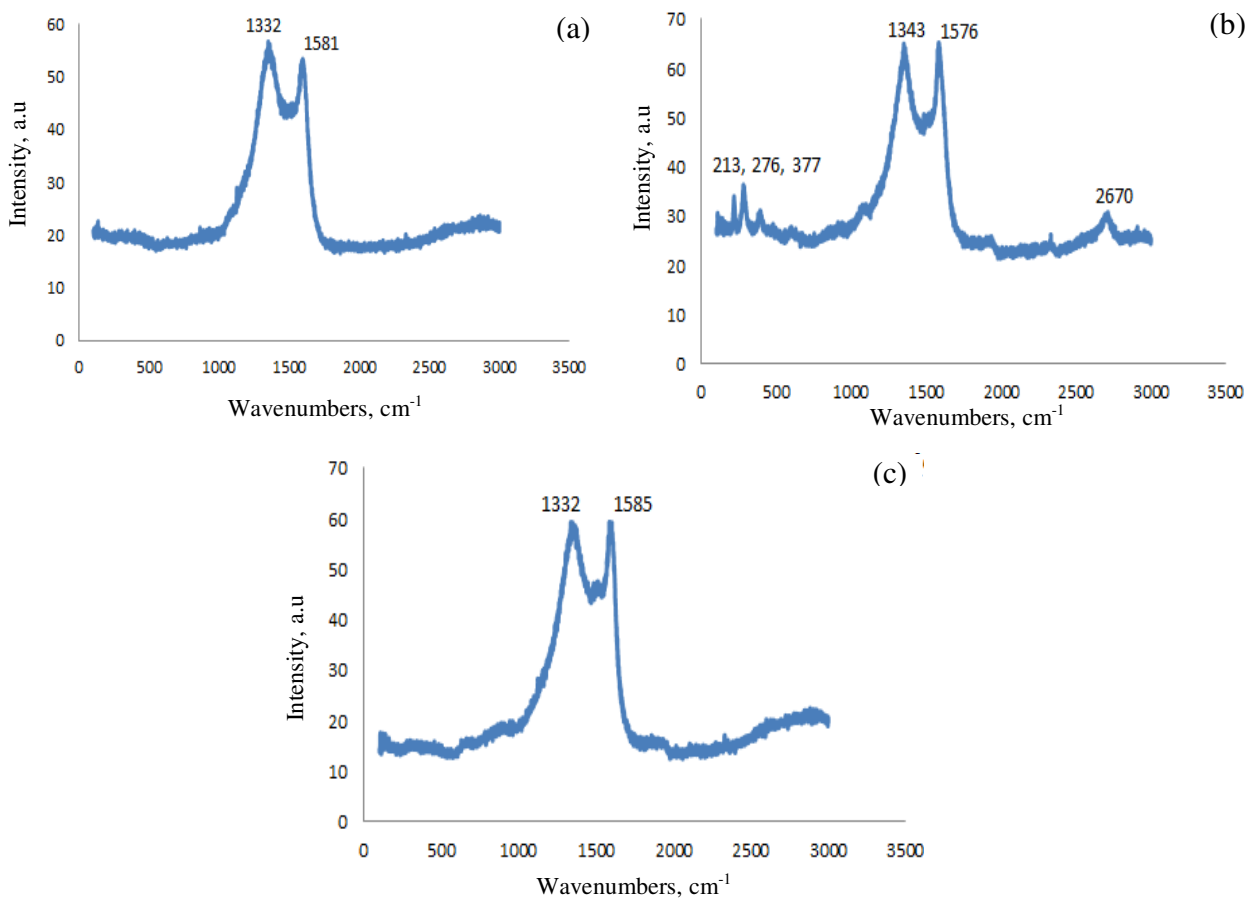

Figure 2. Raman spectra of carbon nanomaterial synthesized with $\mathrm{Mo} / \mathrm{Fe}$ catalyst on (a) aluminium oxide, (b) calcium carbonate and (c) magnesium oxide support 
Table 2. Table of $D$ - and $G$-band peak height and intensity, overtone band peak height and intensity and ratio of $D$ - and $G$-bands obtained from Raman spectra of carbon nanotube synthesized with $\mathrm{Mo} / \mathrm{Fe}$ catalyst on different support

\begin{tabular}{lccccccc}
\hline & \multicolumn{2}{c}{$D$-Band } & \multicolumn{3}{c}{ G-Band } & \multicolumn{3}{c}{ Overtone-band } & $I_{D} / I_{G}$ \\
\cline { 2 - 8 } $\begin{array}{c}\text { Catalyst and } \\
\text { support }\end{array}$ & $\begin{array}{c}\text { Peak } \\
\mathrm{cm}^{-1}\end{array}$ & $\begin{array}{c}\text { Intensity, } \\
\text { au }\end{array}$ & $\begin{array}{c}\text { Peak, } \\
\mathrm{cm}^{-1}\end{array}$ & $\begin{array}{c}\text { Intensity, } \\
\text { au }\end{array}$ & $\begin{array}{c}\text { Peak, } \\
\mathrm{cm}^{-1}\end{array}$ & $\begin{array}{c}\text { Intensity, } \\
\text { au }\end{array}$ \\
\hline $\mathrm{Mo} / \mathrm{Fe} / \mathrm{Al}_{2} \mathrm{O}_{3}$ & 1332 & 55.17 & 1581 & 52.38 & - & - & 1.0533 \\
$\mathrm{Mo} / \mathrm{Fe} / \mathrm{CaCO}_{3}$ & 1343 & 63.34 & 1576 & 63.64 & 2670 & 28.95 & 0.9953 \\
$\mathrm{Mo} / \mathrm{Fe} / \mathrm{MgO}$ & 1332 & 57.75 & 1585 & 59.24 & - & - & 0.9748 \\
\hline
\end{tabular}

A comparison of the Raman spectra of the support material with the catalyst and support show the scope of interaction between the support and the catalyst. We observe that in the absence of the catalyst, aluminium oxide, calcium carbonate and magnesium oxide supports, Figure 1(a-c), produce a significant peak at 1121 and $1122 \mathrm{~cm}^{-1}$, which is absent in the spectra of the catalyst and support, Figure 2(a-c). The presence of the catalyst in the synthesis provides an interaction that eliminates this peak. This peak at 1121 and $1122 \mathrm{~cm}^{-1}$ is most prominent in the spectra for calcium carbonate and magnesium oxide supports. The Raman spectra of the support material with the catalyst and support show shifts in the $D$ - and $G$-bands. In the support materials, the $D$ - and $G$ bands are observed at low wavenumbers while in the spectra of the catalyst and support, the $D$ - and $G$-bands are observed at higher wavenumbers. The change in the resonance wavenumbers show the presence of $s p^{2}$ bonded carbon atoms in the asprepared sample. Using the $514.5 \mathrm{~nm}$ laser excitation, and the McNamara et al formula: ${ }^{22}$

$$
f=\frac{100 x I_{G}}{75 x I_{D}+I_{G}}
$$

Where $I_{D}$ is the intensity of the $D$-band at about $1332 \mathrm{~cm}^{-1}$ and $I_{G}$ is the intensity of the $G$-band at about $1550 \mathrm{~cm}^{-1}$ attributed to $\mathrm{C}=\mathrm{C} s p^{2}$ bond stretching mode and $f$ is the $s p^{2} / s p^{3}$ bond ratio. The $s p^{2} / s p^{3}$ ratio bond for the as-prepared nanomaterial on a support without a catalyst and that of catalyst with support is presented in Figure 3. The figure show the ratio of $s p^{2} / s p^{3}$ bonded carbon to be highest in calcium carbonate and lowest in aluminium in the as-prepared nanomaterial without a catalyst. With the as-prepared nanomaterial on a catalyst and support, the ratio is highest in $\mathrm{Mo} / \mathrm{Fe} / \mathrm{MgO}$ and lowest in $\mathrm{Mo} / \mathrm{Fe} / \mathrm{Al}_{2} \mathrm{O}_{3}$.

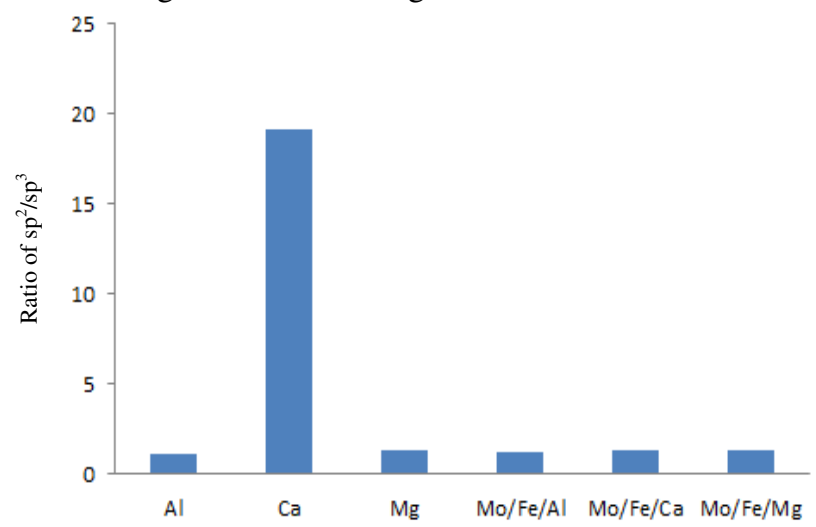

Figure 3. Ratio of $s p^{2} / s p^{3}$ bonded carbon present in the as-prepared carbon nanomaterial. 
TGA analysis was employed to examine the thermal stability of the as-prepared carbon nanomaterial obtained from $\mathrm{Mo} / \mathrm{Fe}$ catalyst on aluminium oxide, calcium carbonate and magnesium oxide support and the as-prepared carbon nanomaterial without catalyst. Thermogravimetric (TGA) and the derivative thermogravimetric (DTG) curve of the weight loss are in most instances used to investigate the presence of carbon nanotubes. The interpretations of these curves are not straight forward due to the presence of catalyst particles during weight loss analysis. The temperature at which carbon nanomaterials are oxidized is an index of their stability. Thermogravimetric and derivative thermogravimetric analysis of support materials, aluminium oxide, calcium carbonate and magnesium oxide are presented in Figure $4(\mathrm{a}-\mathrm{c})$. The thermogravimetric analysis of aluminium oxide and calcium carbonate, Figure $4(\mathrm{a} \& \mathrm{~b})$, show weight loss of about $7 \%$. The TGA curve decreases steadily from the start without any exothermic or endothermic reaction. The derivative thermogravimetric analysis (DTA), curve show no thermal event taking place in the analysis showing a straight line curve. The thermogravimetric and derivative thermogravimetric analysis for magnesium oxide, Figure 4(c), on the other hand show a weight loss of $37.39 \%$. The weight loss started from $601.35-831.83{ }^{\circ} \mathrm{C}$ indicating decomposition of formed carbonaceous material. The DTA show an endothermic peak at $692.89^{\circ} \mathrm{C}$ corresponding to a single decomposition reaction.

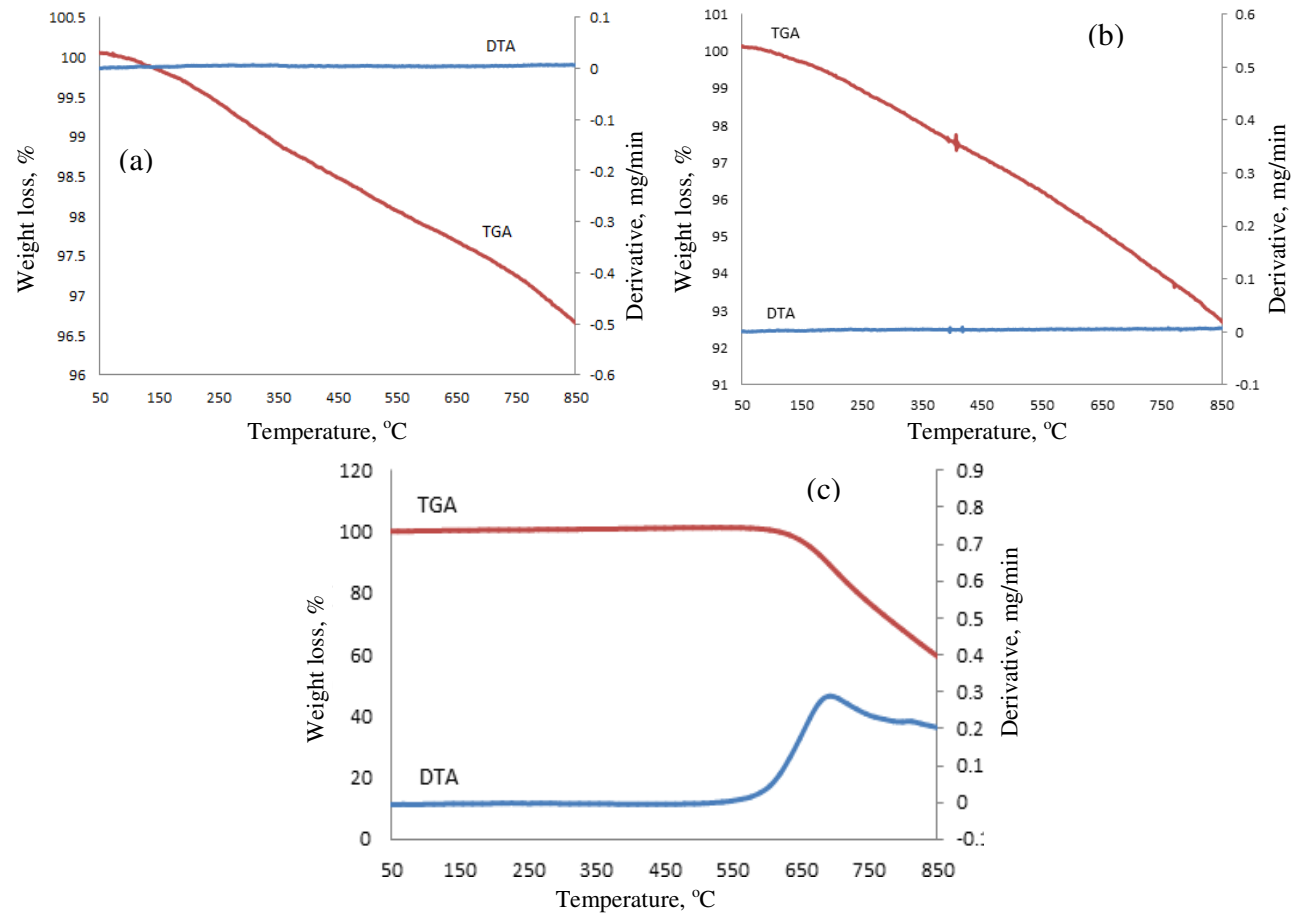

Figure 4. Thermogravimetric and derivative thermogravimetric analysis of as-prepared carbon nanomaterial obtained from support material from 50-850 ${ }^{\circ} \mathrm{C}$. (a) Aluminium oxide, (b) calcium carbonate and (c) magnesium oxide

Thermogravimetric and derivative thermogravimetric analysis of carbon nanomaterial obtained with the catalyst $\mathrm{Mo} / \mathrm{Fe}$ supported on aluminium oxide, calcium carbonate and magnesium oxide are presented in Figure 5(a-c). The TGA curve for $\mathrm{Mo} / \mathrm{Fe} / \mathrm{Al}_{2} \mathrm{O}_{3}$, Figure 5(a), shows a one-step decomposition reaction. Weight loss started at $521.6^{\circ} \mathrm{C}$ and ended at $687.7^{\circ} \mathrm{C}$ 
giving rise to $11 \%$ weight loss. The derivative thermogravimetric analysis (DTA) show a single endothermic peak at $608{ }^{\circ} \mathrm{C}$. The product show high stability and the low weight loss indicate the presence of low amorphous soot in the product. The TGA curve for $\mathrm{Mo} / \mathrm{Fe} / \mathrm{CaCO}_{3}$, Figure $5(\mathrm{~b})$, shows a gradual decrease in temperature from the start to $700{ }^{\circ} \mathrm{C}$. A small decomposition reaction from 353.21-392.02 ${ }^{\circ} \mathrm{C}$, which did not produce either an endothermic or exothermic change in the DTA curve, is observed. The TGA curve for $\mathrm{Mo} / \mathrm{Fe} / \mathrm{MgO}$, Figure $5(\mathrm{c})$, shows a gradual decrease in temperature from the start to $800{ }^{\circ} \mathrm{C}$. Neither decomposition reaction nor an endothermic or exothermic change in the DTA curve, is observed.
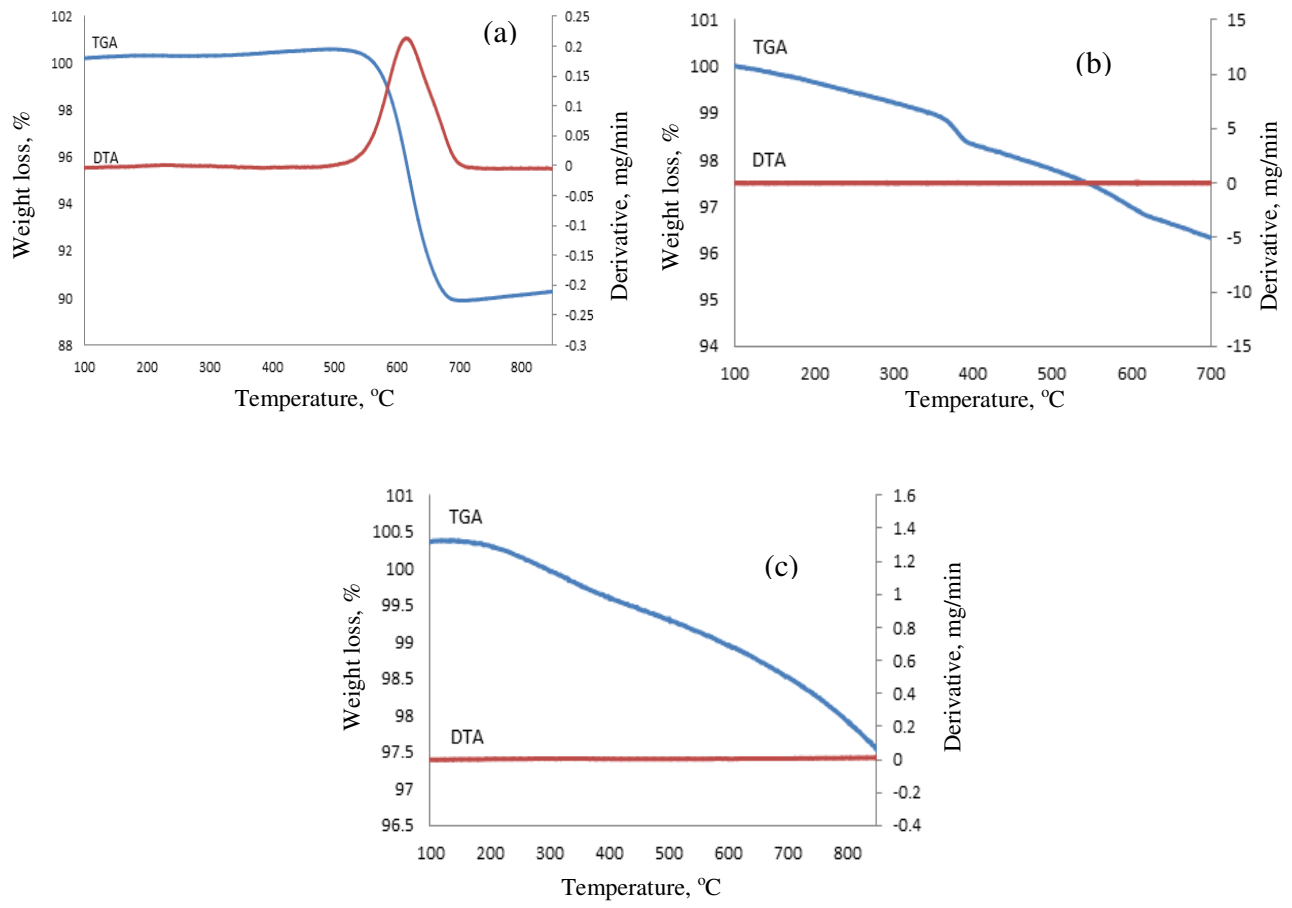

Figure 5. Thermogravimetric and derivative thermogravimetric analysis of as-prepared carbon nanomaterial obtained from the catalyst $\mathrm{Mo} / \mathrm{Fe}$ supported on (a) aluminium oxide, (b) calcium carbonate and (c) magnesium oxide

Scanning electron microscope of as prepared carbon nanomaterial obtained with support materials only and catalysts on support material are presented in Figure 6 and 7. The images show a few strands of nanomaterial obtained from the synthesis procedure. These strands of nanomaterial support the Raman spectra result that indicated the presence of D- and G- bands in the as-prepared samples that suggests the presence amorphous and ordered graphitic carbon. Nanospheres and nanotubes are observed in Figure 7(c) when $\mathrm{Mo} / \mathrm{Fe}$ supported on magnesium oxide is used in the synthesis.

Energy dispersive spectroscopy (EDS) of the Mo/Fe catalyst supported on aluminium oxide, calcium carbonate and magnesium oxide are presented in Figure 8. All spectra show the presence of the elements carbon, oxygen and the elements aluminium, Figure 8(a), calcium, Figure 8(b) and magnesium, Figure 8(c). These spectra give credence to the presence of carbon nanomaterial formed in the synthesis. The intensity of the carbon peak in Figure $8(\mathrm{a}-\mathrm{c})$ is in agreement with the scanning electron micrograph result, Figure 7(a-c), that show the amount of carbon nanomaterial formed. 


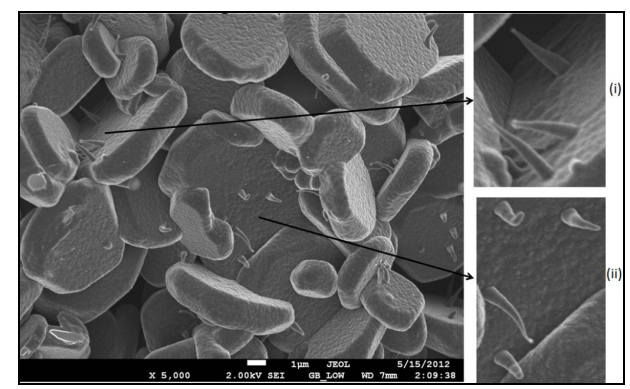

(a)

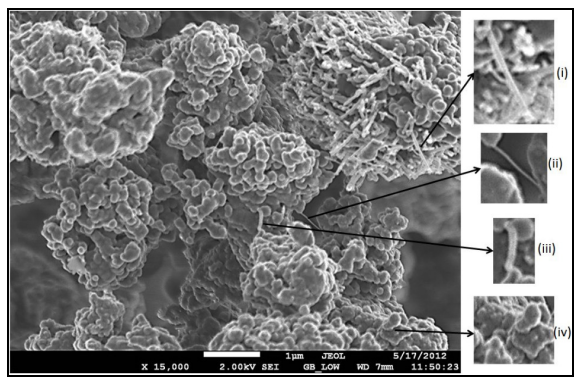

(b)

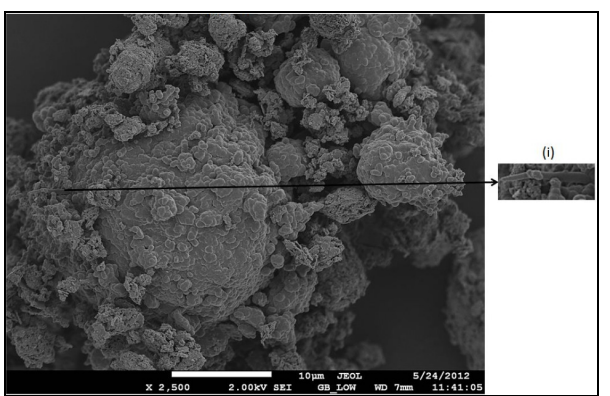

(c)

Figure 6. Scanning Electron Microscope (SEM) of as-prepared carbon nanomaterial obtained from support material from $50-850{ }^{\circ} \mathrm{C}$. (a) Aluminium oxide, (b) calcium carbonate and (c) magnesium oxide

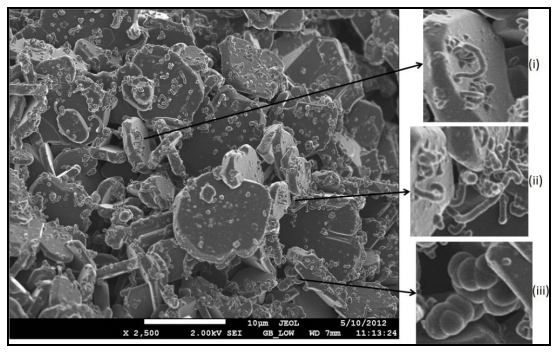

(a)

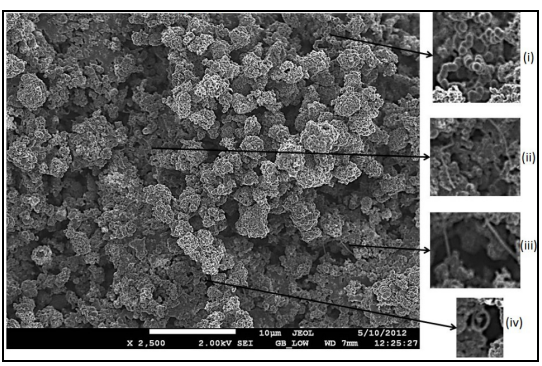

(b)

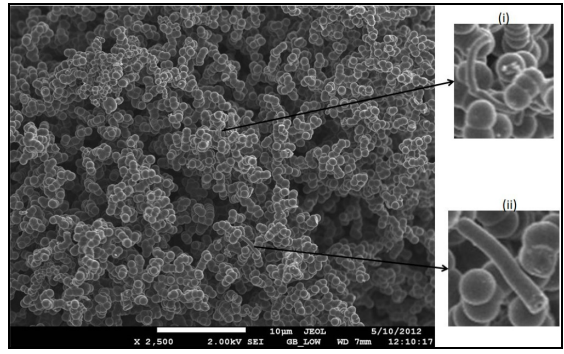

(c)

Figure 7. Scanning Electron Microscope (SEM) analysis of as-prepared carbon nanomaterial obtained from the catalyst $\mathrm{Mo} / \mathrm{Fe}$ supported on (a) aluminium oxide, (b) calcium carbonate and (c) magnesium oxide 

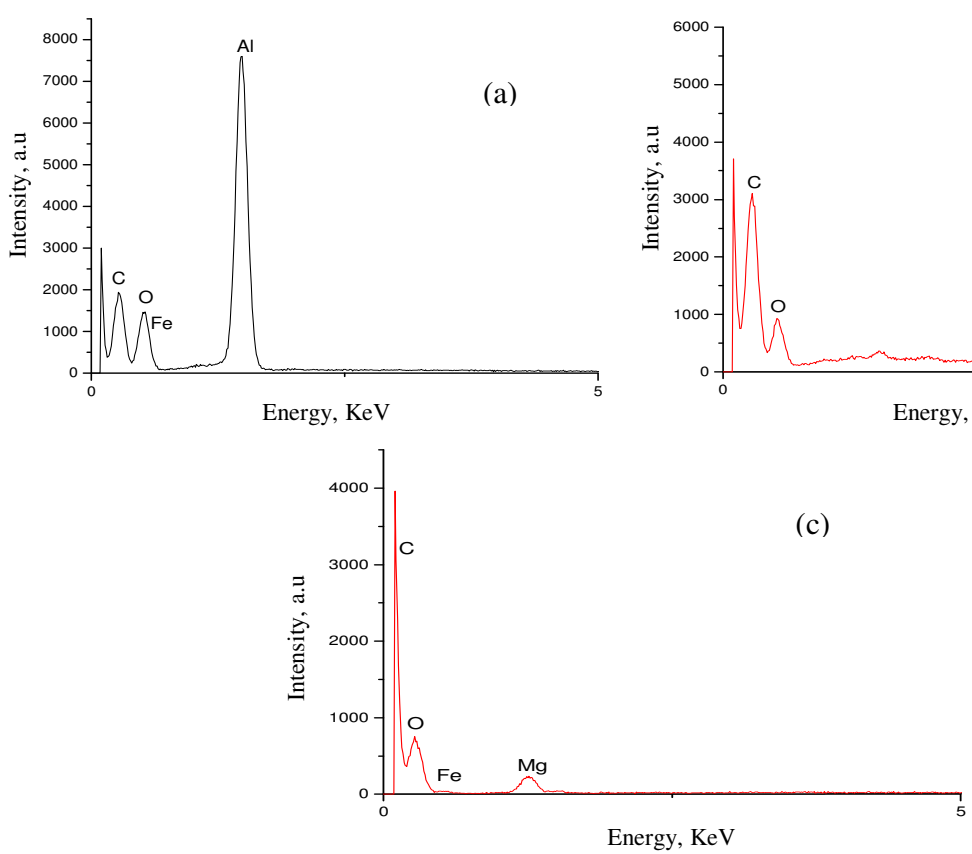

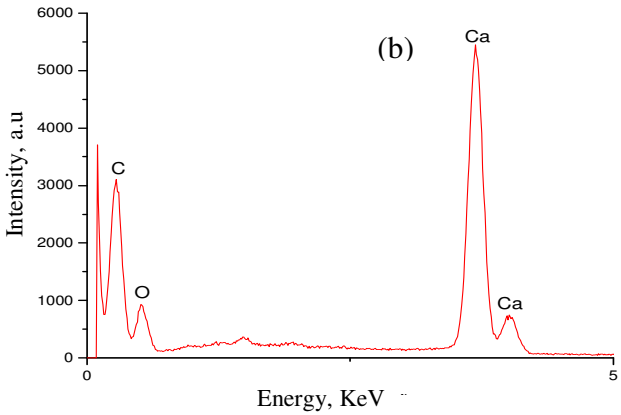

Figure 8. Energy Dispersive Spectroscopic (EDS) analysis of as-prepared carbon nanomaterial obtained from the catalyst $\mathrm{Mo} / \mathrm{Fe}$ supported on (a) aluminium oxide, (b) calcium carbonate and (c) magnesium oxide.

Figure 9 show the transmission electron micrograph (TEM) of nanomaterial obtained from the catalyst $\mathrm{Mo} / \mathrm{Fe}$ supported on aluminium oxide, calcium carbonate and magnesium oxide. Figure 9 (b and c) show cylindrical nanotubes with inset that indicate the lattice structure of the nanotubes formed in the synthesis.

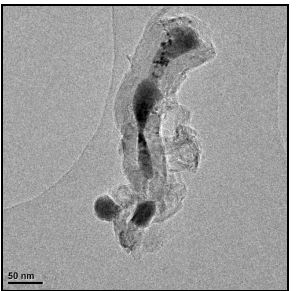

(a)

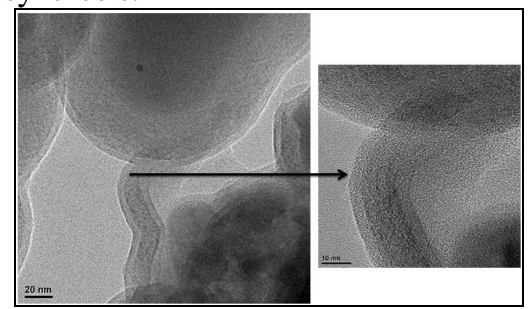

(b)

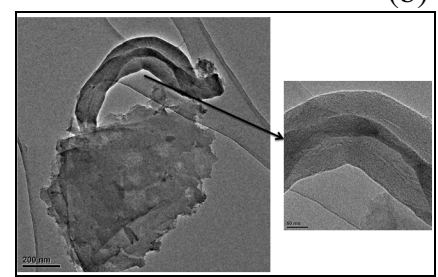

(c)

Figure 9. Transmission Electron Microscope (TEM) analysis of as-prepared carbon nanomaterial obtained from the catalyst $\mathrm{Mo} / \mathrm{Fe}$ supported on (a) aluminium oxide, (b) calcium carbonate and (c) magnesium oxide 
$\mathrm{X}$ ray diffraction (XRD) of as prepared carbon nanomaterials obtained with support materials only and catalysts on aluminium oxide, calcium carbonate and magnesium oxide as support material are presented in Figure 10 and 11. The diffractogram presented in Figure 10(a-c) show several Bragg diffraction peaks with the most notable at $2 \theta=22.79^{\circ}$, $24.18^{\circ}$ and $42.83^{\circ}$. The peaks at $2 \theta=22.79^{\circ}, 24.18^{\circ}$ and $42.83^{\circ}$ correspond to hexagonal graphite lattice of multi-walled carbon nanotubes. The peaks at $2 \theta=22.79^{\circ}$ and $24.18^{\circ}$, Figure 10(b and c) are low intensity peaks which indicate the presence of small amounts of amorphous material in association with nanotubes. The high intensity of the peak at $2 \theta=$ $42.83^{\circ}$, Figure $10(\mathrm{c})$, is an indication of the high quality of carbon nanomaterial present in the as-prepared carbon nanomaterial. The diffraction presented in Figure 11(a-c) also show several Bragg diffraction peaks with the most notable at $2 \theta=23.50^{\circ}, 23.71^{\circ}$ and $42.80^{\circ}$. The peaks at $2 \theta=23.50^{\circ}$ and $23.71^{\circ}$, Figure $11(\mathrm{~b}$ and $\mathrm{c}$ ) are low intensity peaks which indicate the presence of small amounts of amorphous material in association with nanotubes. The high intensity of the peak at $2 \theta=42.80^{\circ}$, Figure $11(\mathrm{c})$, is an indication of the high quality of carbon nanomaterial present in the as-prepared carbon nanomaterial.

A comparison of the XRD peaks obtained from the as prepared carbon nanomaterials obtained with support materials only and catalysts on aluminium oxide, calcium carbonate and magnesium oxide as support material are presented in Table 3 and 4 . The tables show the shifts in the Bragg diffraction peaks and intensity for the carbon nanomaterial obtained in the synthesis.
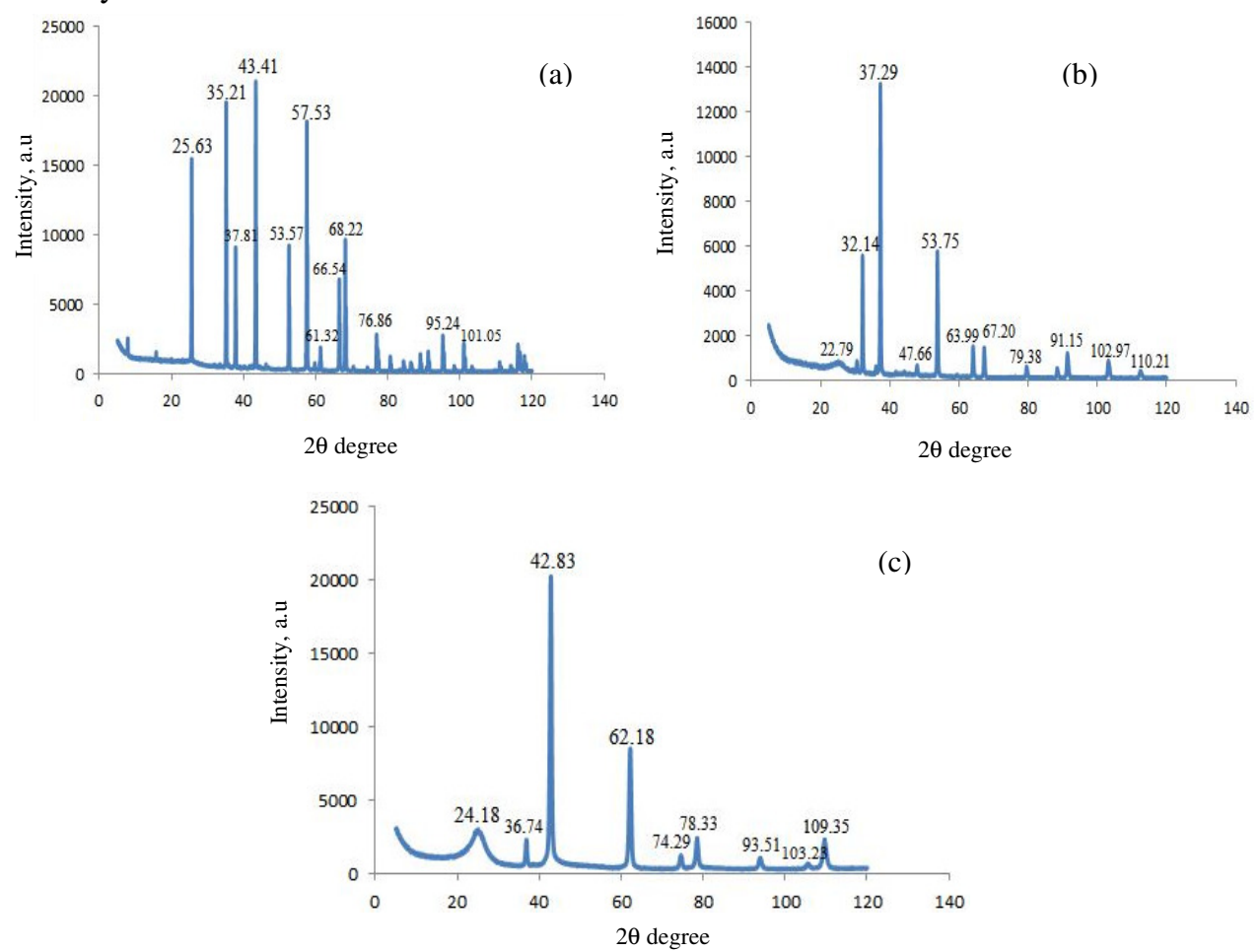

Figure 10. X-Ray Diffraction (XRD) analysis of as-prepared carbon nanomaterial obtained from support material from $50-850{ }^{\circ} \mathrm{C}$. (a) Aluminium oxide, (b) calcium carbonate and (c) magnesium oxide 

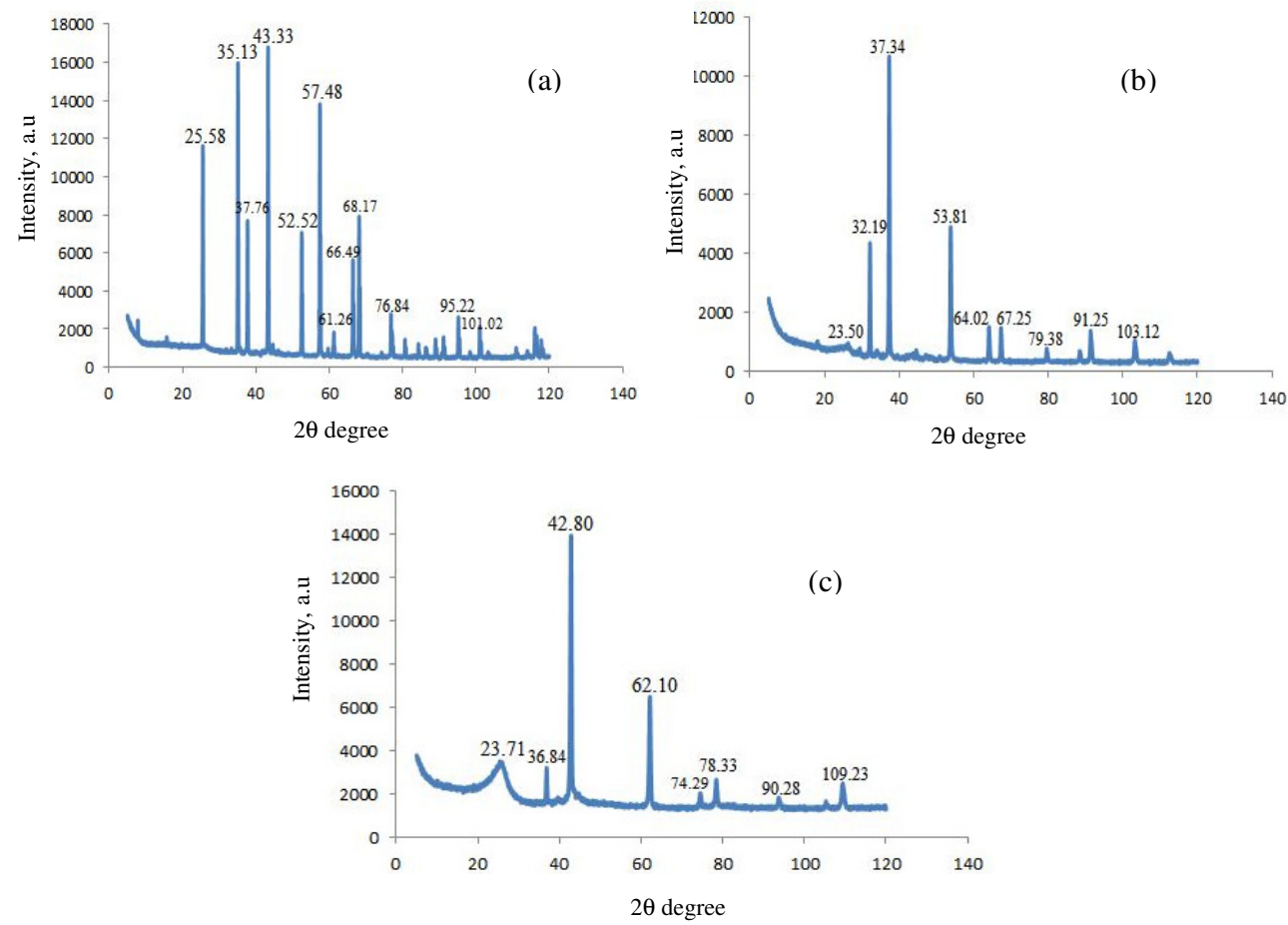

Figure 11. X-ray Diffraction (XRD) analysis of as-prepared carbon nanomaterial obtained from the catalyst $\mathrm{Mo} / \mathrm{Fe}$ supported on (a) aluminium oxide, (b) calcium carbonate and (c) magnesium oxide

Table 3. Comparison XRD peaks obtained from as-prepared carbon nanotubes from $\mathrm{Al}_{2} \mathrm{O}_{3}$, $\mathrm{CaCO}_{3}$ and $\mathrm{MgO}$

\begin{tabular}{ccccc}
\hline Sample & \multicolumn{2}{c}{ Amorphous carbon } & \multicolumn{2}{c}{ Nanomaterial } \\
\cline { 2 - 5 } name & 2 Theta, degree & Intensity, a.u & 2 Theta, degrees & Intensity, a.u \\
\hline $\mathrm{Al}_{2} \mathrm{O}_{3}$ & 25.63 & 15492 & 43.41 & 20703 \\
$\mathrm{CaCO}_{3}$ & 22.79 & 646 & 37.29 & 13227 \\
$\mathrm{MgO}$ & 24.18 & 2351 & 42.83 & 19937 \\
\hline
\end{tabular}

Table 4. Comparison XRD peaks obtained from as-prepared carbon nanotubes from $\mathrm{Mo} / \mathrm{Fe} / \mathrm{Al}_{2} \mathrm{O}_{3}, \mathrm{Mo} / \mathrm{Fe} / \mathrm{CaCO}_{3}$ and $\mathrm{Mo} / \mathrm{Fe} / \mathrm{MgO}$

\begin{tabular}{ccccc}
\hline \multirow{2}{*}{ Sample name } & \multicolumn{2}{c}{ Amorphous Carbon } & \multicolumn{2}{c}{ Nanomaterial } \\
\cline { 2 - 5 } & 2theta, degree & Intensity, a.u & 2 Theta, degrees & Intensity, a.u \\
\hline $\mathrm{Mo} / \mathrm{Fe} / \mathrm{Al}_{2} \mathrm{O}_{3}$ & $25.58^{\circ}$ & 11553 & $43.33^{\circ}$ & 16756 \\
$\mathrm{Mo} / \mathrm{Fe} / \mathrm{CaCO}_{3}$ & $23.50^{\circ}$ & 817 & $37.34^{\circ}$ & 10664 \\
$\mathrm{Mo} / \mathrm{Fe} / \mathrm{MgO}$ & $23.71^{\circ}$ & 3096 & $42.80^{\circ}$ & 13710 \\
\hline
\end{tabular}

\section{Conclusion}

In summary, carbon nanomaterials were synthesized with catalyst on support material and with support and no catalyst. The support material without catalyst produced nanomaterial with $s p^{2} / s p^{3}$ bonded carbon and carbonaceous material as observed in the $D$ - and $G$-bands. Raman spectra of carbon nanomaterial obtained from $\mathrm{Al}_{2} \mathrm{O}_{3}, \mathrm{CaCO}_{3}$ and $\mathrm{MgO}$ without catalyst 
showed significantly the presence of poor quality carbon nanotubes with high defects levels hence the intensity ratio, $\left(I_{D} / I_{G}\right)$, for $\mathrm{Al}_{2} \mathrm{O}_{3}$ and $\mathrm{MgO}$ was found to be 1.142 and 1.014 respectively, on the other hand, Raman spectra carbon nanomaterial obtained from $\mathrm{CaCO}_{3}$ gave evidence for the presence of high quality carbon nanomaterial with less defects with intensity ratio 0.056 . Raman spectra for nanomaterial synthesized with catalyst and support, $\mathrm{Mo} / \mathrm{Fe} / \mathrm{Al}_{2} \mathrm{O}_{3}, \mathrm{Mo} / \mathrm{Fe} / \mathrm{CaCO}_{3}$ and $\mathrm{Mo} / \mathrm{Fe} / \mathrm{MgO}$ show the influence of the catalyst in the synthesis. The peaks for the $D$ - and $G$-bands were shifted to higher wavenumbers. The intensity ratios, $\left(I_{D} / I_{G}\right)$, were lower than that obtained from the support only. The $s p^{2} / s p^{3}$ bonded carbon ratios were significantly low. TGA and DTA curves of the carbon nanomaterial from $\mathrm{Al}_{2} \mathrm{O}_{3}$ and $\mathrm{CaCO}_{3}$ show partial decomposition when subjected to high temperatures, while $\mathrm{MgO}$ lost about $37,39 \%$ of its mass indicating decomposition of synthesized carbonaceous materials. $\mathrm{Mo} / \mathrm{Fe} / \mathrm{CaCO}_{3}$ and $\mathrm{Mo} / \mathrm{Fe} / \mathrm{MgO}$ barely decomposed under high temperatures while $\mathrm{Mo} / \mathrm{Fe} / \mathrm{Al}_{2} \mathrm{O}_{3}$ lost $11 \%$ of its mass. The presence of catalyst stabilised and assisted in the synthesis of carbon nanomaterial. Scanning electron microscope and X-ray diffraction confirm the presence of carbon nanomaterial and an indication of the amount produced.

\section{Acknowledgment}

This work was supported by a research grant from the Faculty of Applied and Computer Science Research and Publications Committee of Vaal University of Technology, Vanderbijlpark.

\section{References}

1. Mehn D, Fonseca A, Bister G and Nagy J B, Chem Phys Lett., 2004, 393(4-6), 378-384.

2. Bouanis F B, Baraton L, Huc V, Pribat D and Cojocaru C S, Thin Solid Films., 2011, 519(14), 4594-4597.

3. $\quad$ Iijima S, Nature, 1999, 56, 354-356.

4. Chaisitsak S, Yamada A and Konagai M, Diamond Relat Mater., 2004, 13(3), 438-444.

5. Jayatissa A H and Guo K. Vacuum, 2009, 83(5), 853-856.

6. $\quad$ Chadderton L T and Ying Chen, Phys Lett A, 1991, 263(4-6), 401-405.

7. Kong J, Cassell A M and Dai H, Chem Phys Lett., 1998, 292(6), 567-574.

8. Yang H, Mercier P, Wang S C and Akins D L, Chem Phys Lett., 2005, 416, 18-21.

9. Dai H, Surf Sci., 2002, 500(1-3), 218-241.

10. Dresselhaus M S, Dresselhaus G and Saito R, Carbon, 1995, 33(7), 883-891.

11. He R R, Jin H Z, Zhu J, Yan Y J and Chen X H, Chem Phys Lett., 1998, 298(1-3), 170-176.

12. Dikio E D, J Chem., 2011, 8(3), 1014-1021.

13. Thaib A, Martin G A, Pinbeiro P, Schouler M C and Gadelle P, Catal Lett., 1999, 63(3-4), 135-141.

14. Konya Z, Nagaraju N, Tamasi A, Mukhopadhyay K M, Fonseca A and Nagy J B, Electrical properties of Nanomaterials-Science and Technology of Molecular Structures: Kuzmany H, Fink J, Mehring M and Roth S, Eds., American Institute of Physics, 1999, 486, 249.

15. Willems I, Konya Z, Colomer J F, Van Tendeloo G, Nagaraju N, Fonseca A and Nagy J B, Chem Phys Lett., 2000, 317(1-2), 71-76. 
16. Benito P, Herrero M, Labajos F M, Rives V, Royo C, Latorre N and Monzon A, Chem Eng J., 2009, 149(1-3), 455-462

17. Colomer J F, Stephen C, Lefrant S, Van Tendeloo G, Willems I, Konya Z, Fonseca A, Laurent Ch and Nagy J B, Chem Phys Lett., 2000, 317(1-2), 83-89.

18. Qingwen L, Hao Y, Yan C, Jin Z and Zhongfan L, J Mater Chem., 2002, 12, 1179- 1183.

19. Tang S, Zhong Z, Xion Z, Sun L, Liu L, Lin J, Shen Z X and Tan K L, Chem Phys Lett., 2001, 350(1-2), 19-26.

20. Wasyluk J, Perova T S, Lau D W M, Taylor M B, McCulloch D G and Stopford J, Diamond Relat Mater., 2010, 19(5-6), 514-517.

21. Ballutaud D, Jomard F, Kociniewski T, Rzepka E, Girard H and Saada S, Diamond Relat Mater., 2008, 17(4-5), 451-456.

22. Costa S, Brorowiak-Palen E, Kruszynska M, Bachmatiuk A and Kaenczuk R J, Mater Sci Poland., 2008, 26(2), 433-441. 